\title{
Níveis crescentes de proteína bruta em suplementos múltiplos para novilhas de corte sob pastejo no período das águas
}

\author{
Increasing levels of crude protein in multiple supplements for \\ grazing beef heifers in rainy season
}

\author{
Lívia Vieira de Barros ${ }^{1 *}$; Mário Fonseca Paulino ${ }^{2}$; Eduardo Henrique Bevitori \\ Kling de Moraes 3 ; Sebastião de Campos Valadares Filho²; Leandro Soares \\ Martins; ; Daniel Mageste de Almeida ${ }^{4}$; Eriton Egídio Lisboa Valente ${ }^{5}$; \\ Carla Heloisa Avelino Cabral'; Sidnei Antônio Lopes ${ }^{4}$; Aline Gomes da Silva ${ }^{4}$
}

\section{Resumo}

Objetivou-se avaliar o efeito de suplementos múltiplos com diferentes teores de proteína bruta sobre, os parâmetros nutricionais, a eficiência de síntese microbiana e o desempenho produtivo de novilhas de corte, em pastagem com Uruchloa decumbens durante o período das águas. Utilizaram-se 39 novilhas Nelore com 14 meses idade e 229,3 $\pm 0,7 \mathrm{~kg}$ de peso corporal. O delineamento foi inteiramente casualizado. Os tratamentos constituíram-se de teores crescentes de proteína bruta nos suplementos e um tratamento controle (MM) no qual os animais receberam apenas mistura mineral. Os suplementos continham 17; 30; 43 e 56\% de proteína bruta $(\mathrm{PB})$, para os tratamentos $\mathrm{PB}_{17} ; \mathrm{PB}_{30} ; \mathrm{PB}_{43}$ e $\mathrm{PB}_{56}$, respectivamente. O ganho médio diário (GMD) (g) foi 447,7; 554,6; 638,4; 587,9; 590,4, respectivamente para os tratamentos $\mathrm{MM}, \mathrm{PB}_{17} ; \mathrm{PB}_{30} ; \mathrm{PB}_{43}$ e $\mathrm{PB}_{56}$. Verificou-se efeito cúbico dos teores de proteína bruta $(\mathrm{P}<0,10)$ sobre o GMD. O GMD foi maior para os animais suplementados $(\mathrm{P}<0,10)$. Observou-se maior consumo de matéria seca (MS), matéria orgânica (MO), $\mathrm{PB}$, extrato etéreo (EE), carboidratos não fibrosos $(\mathrm{CNF})$, nutrientes digestíveis totais (NDT) e matéria seca digerida $(\mathrm{P}<0,10)$ para os animais suplementados. Entre os teores de proteína bruta nos suplementos observou-se redução no consumo de MS de forragem com a elevação do teor de PB no suplemento. A suplementação aumentou o coeficiente de digestibilidade aparente da MS, PB, EE e CNF. Houve efeito quadrático do teor de proteína bruta nos suplementos sobre a digestibilidade da MS e EE e efeito cúbico sobre a digestibilidade da MO, fibra em detergente neutro, CNF e para o teor de NDT. Não houve diferença em relação à eficiência de síntese de proteína microbiana (EFIM) entre animais suplementados e não suplementados. Houve efeito linear positivo do teor de PB no suplemento sobre a EFIM. O fornecimento de suplementos múltiplos para novilhas, manejadas a pasto com média a alta qualidade durante o período das águas, melhora o desempenho produtivo dos animais. O fornecimento de suplementos com altos teores de PB durante o período das águas diminui o consumo de forragem.

Palavras-chave: Desempenho, fêmeas, forragem, suplementação

1 Prof ${ }^{\text {a }}$ Universidade Federal do Mato Grosso, UFMT, Cuiabá, MT. E-mail: liviavieiradebarros@gmail.com

Profs., Universidade Federal de Viçosa, UFV, Viçosa, MG. E-mail: mpaulino@ufv.br; scvfilho@ufv.br

Prof., UFMT, Sinop, MT. E-mail: edukling@ufmt.br

4 Discentes do Curso de Doutorado em Zootecnia; UFV, Viçosa, MG. E-mail: leandro_martins@yahoo.com.br; danielmagestedealmeida@yahoo.com.br; sidneyufv@hotmail.com; alinegomesdasilva@rocketmail.com

5 Prof., Universidade Estadual do Oeste do Paraná, UNIOESTE, Marechal Candido Rondon, PR. E-mail: eritonvalente@yahoo. com.br

6 Prof ${ }^{a}$, UFMT, Rondonópilis, MT. E-mail: cabralcha@hotmail.com

* Autor para correspondência 


\begin{abstract}
The objective was to evaluate the effect of multiple supplements with differents levels of crude protein (CP) or mineral supplements on the nutritional parameters and performance of beef heifers grazing Uruchloa decumbens in the rainy season. A complete random design was employed. The treatments were made up of increasing levels of $\mathrm{CP}$ in the multiple supplements and a control treatment (MM) in which animals were offered only mineral mixture. Multiple supplements contained 17;30; 43 and $56 \%$ of $\mathrm{CP}$, for treatments CP17; CP30; CP43 and CP56, respectively. Average daily gain (ADG) (g) was 447.7; 554.6; 638.4; 587.9; 590.4, for treatments MM, CP17; CP30; CP43 and CP56, respectively. A quadratic effect of the levels of crude protein was found $(p<0.10)$ on ADG. A greater intake of dry matter $(\mathrm{DM})$, organic matter $(\mathrm{OM}), \mathrm{CP}$, ether extract (EE), non-fibrous carbohydrates (NFC), total digestible nutrients $(\mathrm{TDN})$, and digested dry matter $(\mathrm{p}<0.10)$ was found in animals supplemented with multiple supplements. Multiple supplements increased the apparent digestibility coefficient of DM, CP, EE and NFC. Supply of multiple multiple supplements for heifers grazing in medium to high quality pastures in the rainy season improves the performance of the animals.
\end{abstract}

Key words: Forage, performance, supplementation

\section{Introdução}

A utilização do pasto pelos animais durante o período das águas em comparação ao período seco não pode ser vista como otimizada considerando apenas o maior desempenho animal (DETMANN; PAULINO; VALADARES FILHO, 2010). Embora os pastos tropicais na época das águas não sejam considerados deficientes em proteína, elevada proporção dos compostos nitrogenados totais do pasto pode ser encontrada na forma insolúvel em detergente neutro (PAULINO; DETMANN; VALADARES FILHO, 2008), considerada de lenta e incompleta degradação, podendo implicar em deficiências de compostos nitrogenados aos microrganismos ruminais.

Em algumas argumentações teóricas relacionadas à nutrição de bovinos em pastejo, afirma-se que a suplementação com compostos nitrogenados prontamente degradáveis no rúmen durante o período de franco crescimento forrageiro não seria capaz de incrementar, ou seria deletéria à produção animal, notadamente em função de ampliação do metabolismo hepático de nitrogênio e do incremento calórico, com redução do consumo voluntário de forragem (POPPI; MCLENNAN, 1995; PAULINO; DETMANN; VALADARES FILHO, 2008). Contudo, resultados obtidos em condições tropicais têm evidenciado que a suplementação com fontes proteicas degradáveis no rúmen (PAULINO; DETMANN; VALADARES FILHO, 2006; FIGUEIREDO et al., 2008), incluindo o uso de ureia como principal composto nitrogenado dos suplementos, tem incrementado o desempenho animal durante o período das águas (DETMANN; PAULINO; VALADARES FILHO, 2010).

Desta forma, o presente trabalho foi conduzido no intuito de avaliar a necessidade de suplementação e o efeito da suplementação com diferentes teores de proteína bruta nos suplementos múltiplos, para novilhas de corte, em pastejo, durante o período das águas sobre o desempenho produtivo, os parâmetros nutricionais e a eficiência de síntese microbiana.

\section{Material e Métodos}

O experimento foi conduzido nas dependências do Setor de Bovinocultura de Corte da Universidade Federal de Viçosa, localizado no município de Viçosa-MG (2045' S e $\left.42^{\circ} 52^{\prime} \mathrm{W}\right)$, entre os meses de dezembro de 2010 a abril de 2011, correspondendo ao período das águas.

O experimento teve duração de 112 dias divididos em quatro períodos experimentais de 28 dias cada. Foram utilizadas 39 novilhas $1 / 2$ sangue Nelore, com idade e pesos médios iniciais, de 14 meses e 229,3 \pm $0,7 \mathrm{~kg}$, respectivamente. 
Foi destinada aos animais uma área experimental com 12,5 hectares, sendo esta constituída por cinco piquetes de 2,5 ha, cobertos uniformemente com a gramínea Uruchloa decumbens, providos de bebedouros e cochos sendo estes cobertos e com acesso pelos dois lados.

O delineamento experimental foi o inteiramente casualizado, com cinco tratamentos, sendo quatro tratamentos com oito repetições e um tratamento com sete repetições.
Foram avaliados quatro suplementos multiplos (Tabela 1) com diferentes teores de proteína bruta. Os teores de proteína bruta avaliados foram 17; 30; 43 e 56 para os tratamentos $\mathrm{PB}_{17}, \mathrm{~PB}_{30}, \mathrm{~PB}_{43}$ e $\mathrm{PB}_{56}$, respectivamente, mais um grupo controle $(\mathrm{MM})$ no qual os animais receberam apenas mistura mineral ad libitum. Em todos os suplementos múltiplos $75 \%$ da proteína bruta foram provenientes do farelo de soja e $25 \%$ da proteína bruta foram provenientes da ureia. Os suplementos foram fornecidos na quantidade de $1,0 \mathrm{~kg}$ por animal por dia.

Tabela 1. Composição $\left(\mathrm{g} \cdot \mathrm{kg}^{-1}\right)$ dos suplementos, com base na matéria natural.

\begin{tabular}{lccccc}
\hline \multicolumn{1}{c}{ Item } & \multicolumn{5}{c}{ Suplementos } \\
\hline & $\mathrm{MM}$ & $\mathrm{PB}_{17}$ & $\mathrm{~PB}_{30}$ & $\mathrm{~PB}_{43}$ & $\mathrm{~PB}_{56}$ \\
\cline { 2 - 6 } Ingredientes & & & & & \\
Mistura mineral $^{1}$ & 1000 & 60 & 60 & 60 & 60 \\
Milho & --- & 758 & 439 & 230 & \\
Farelo de soja & --- & 170 & 485 & 675 & 886 \\
Ureia/ SA (9:1) & --- & 12 & 16 & 35 & 54 \\
\hline
\end{tabular}

${ }^{1}$ Composição percentual: fosfato bicálcico, 50,00; cloreto de sódio, 47,775; sulfato de zinco, 1,40; sulfato de cobre, 0,70; sulfato de cobalto, 0,05; iodato de potássio, 0,05 e selenito de sódio 0,025 .

MM: Mistura mineral; PB17: suplemento múltiplo com 17\% de proteína bruta; PB30: suplemento múltiplo com 30\% de proteína bruta; PB43: suplemento múltiplo com 43\% de proteína bruta e PB56: suplemento múltiplo com 56\% de proteína bruta.

Fonte: Elaboração dos autores.

Os suplementos foram fornecidos diariamente às $10 \mathrm{~h} 00$, em comedouro conjunto, com dois metros de comprimento e acesso por ambos os lados, a fim de permitir o acesso simultâneo de todos os animais. A água foi disponibilizada ad libitum durante todo o experimento.

Ao início do experimento, todos os animais foram submetidos ao controle de ecto e endoparasitas e durante o período experimental, quando necessário.

Os animais foram pesados no início do experimento após jejum hídrico e alimentar de 14 horas; logoapós, os tratamentos foram aleatoriamente designados às unidades experimentais (animais). Formaram-se cinco lotes, agrupando-se os animais que receberiam o mesmo tratamento.

A cada sete dias os animais foram rotacionados entre os piquetes, visando o controle de possíveis efeitos de piquetes sobre os tratamentos (disponibilidade de pasto, localização da aguada e cocho, relevo, sombreamento, etc); o tratamento acompanhou o grupo de animais.

O ganho médio diário (GMD) de peso das novilhas foi calculado pela diferença entre o peso final e o inicial, ambos realizados após jejum hídrico e alimentar de 14 horas, dividido pelo número de dias experimentais.

A amostragem para avaliação qualitativa do pasto consumido pelos animais foi realizada via simulação manual de pastejo a cada 14 dias. Essa amostra foi pesada e levada imediatamente à estufa com circulação forçada de ar a $60^{\circ} \mathrm{C}$ por 72 horas e moída em moinho de facas (1 mm).

No décimo quinto dia de cada período experimental foi realizada coleta do pasto para 
quantificação da massa de matéria seca e de matéria seca potencialmente digestível (MSpd), através do corte rente ao solo de quatro áreas delimitadas por um quadrado metálico de $0,5 \times 0,5 \mathrm{~m}$, selecionados aleatoriamente em cada piquete experimental. Essa amostra também foi pesada e levada imediatamente à estufa com circulação forçada de ar a $60^{\circ} \mathrm{C}$ por 72 horas.

A MSpd foi estimada segundo a seguinte equação (PAULINO; DETMANN; VALADARES FILHO, 2008):

$$
\mathrm{MSpd}=0,98 \times(100-\mathrm{FDNcp})+(\mathrm{FDNcp}-\mathrm{FDNi})
$$

Para a avaliação das características nutricionais, das novilhas a partir do $45^{\circ}$ dia do período experimental foi realizado um ensaio com duração de nove dias. Utilizou-se o método de três indicadores. Para estimar a excreção fecal, foi fornecido aos animais o indicador externo óxido crômico $\left(\mathrm{Cr}_{2} \mathrm{O}_{3}\right)$, acondicionado em cartuchos de papel, correspondente a $15 \mathrm{~g}$ por novilha.dia ${ }^{-1}$, aplicado com auxílio de uma sonda metálica diretamente no esôfago, sempre às $10 \mathrm{~h} 00$. Para estimar o consumo individual de suplemento pelas novilhas foi utilizado o dióxido de titânio $\left(\mathrm{TiO}_{2}\right)$ fornecido via suplemento na proporção de $10 \mathrm{~g}$ de indicador. $\mathrm{kg}^{-1}$ de suplemento. Para estimar o consumo de MS de pasto foi utilizado como indicador interno a FDNi.

Dos nove dias do ensaio, seis foram destinados à adaptação ao $\mathrm{Cr}_{2} \mathrm{O}_{3}$ e ao $\mathrm{TiO}_{2}$. Nos últimos três dias foram realizadas coletas de fezes em horários diferenciados, às $15 \mathrm{~h} 00,11 \mathrm{~h} 00$ e às $7 \mathrm{~h} 00$, respectivamente. As amostras de fezes foram coletadas imediatamente após a defecação ou diretamente no reto dos animais, em quantidades aproximadas de $200 \mathrm{~g}$, sendo identificadas por animal e secas em estufa com circulação forçada de ar a $60^{\circ} \mathrm{C}$ por 72 horas e após a secagem, moídas em moinho de facas $(1 \mathrm{~mm})$.

No quinto dia do ensaio foi realizada uma simulação manual de pastejo, em cada piquete separadamente, sendo estas amostras usadas para a estimação do consumo e dos coeficientes de digestibilidade dos componentes da ração suplementar. A composição do suplemento e da forragem obtida é apresentada na Tabela 2.

Tabela 2. Composição química dos suplementos e da Uruchloa decumbens.

\begin{tabular}{|c|c|c|c|c|c|c|}
\hline \multirow{2}{*}{ Item $^{1}$} & \multicolumn{4}{|c|}{ Suplementos } & \multirow[b]{2}{*}{ U. decumbens ${ }^{5}$} & \multirow[b]{2}{*}{ U. decumbens ${ }^{6}$} \\
\hline & $\mathrm{PB}_{17}$ & $\mathrm{~PB}_{30}$ & $\mathrm{~PB}_{43}$ & $\mathrm{~PB}_{56}$ & & \\
\hline Matéria Seca ${ }^{2}$ & 948,90 & 945,10 & 941,30 & 937,40 & $259,9 \pm 2,96^{7}$ & $237,2 \pm 1,37$ \\
\hline Matéria Orgânica ${ }^{3}$ & 920,6 & 905,3 & 896,2 & 886,1 & $921,1 \pm 0,54$ & $915,3 \pm 0,51$ \\
\hline Proteína Bruta ${ }^{3}$ & 179 & 313 & 433 & 562 & $126,6 \pm 1,04$ & $124,1 \pm 0,44$ \\
\hline $\mathrm{NIDN}^{4}$ & 218,4 & 266,1 & 291,5 & 320,1 & $251,5 \pm 2,01$ & $282,8 \pm 1,75$ \\
\hline Extrato Etéreo ${ }^{3}$ & 31,6 & 22,8 & 16,8 & 10,3 & $15,4 \pm 0,13$ & $19,5 \pm 0,15$ \\
\hline FDNcp $^{1,3}$ & 104 & 125 & 123 & 121 & $595,4 \pm 1,92$ & $558,6 \pm 1,21$ \\
\hline Carboidratos não Fibrosos ${ }^{3}$ & 687 & 533,3 & 445,4 & 349,8 & $183,7 \pm 0,91$ & $213,1 \pm 0,47$ \\
\hline FDAcp $^{1,3}$ & 20,6 & 34,5 & 42,6 & 51,7 & $264,4 \pm 0,85$ & $250,4 \pm 0,35$ \\
\hline $\mathrm{NNP}^{4}$ & 158,1 & 155,3 & 150,8 & 146,2 & $337,7 \pm 3,74$ & $263,4 \pm 0,97$ \\
\hline $\mathrm{FDNi}^{1,3}$ & 9,6 & 7,2 & 5,6 & 3,8 & $186,5 \pm 2,29$ & $184,3 \pm 0,41$ \\
\hline Lignina $^{1,3}$ & 11,7 & 20,6 & 28,6 & 27,1 & $41,4 \pm 0,51$ & $41,2 \pm 0,20$ \\
\hline
\end{tabular}

1/NIDN - nitrogênio insolúvel em detergente neutro; FDNcp - fibra em detergente neutro corrigida para cinzas e proteína; FDAcp - fibra em detergente ácido corrigida para cinzas e proteína; FDNi - fibra em detergente neutro indigestível. ${ }^{2} / \mathrm{Em} \mathrm{g} / \mathrm{kg}$ de matéria natural. ${ }^{3 / \mathrm{Em}} \mathrm{g} / \mathrm{kg}$ de matéria seca. ${ }^{4 / \mathrm{Em}} \mathrm{g} \cdot \mathrm{kg}^{-1}$ de nitrogênio total. ${ }^{5} /$ Média das amostras obtidas por simulação manual do

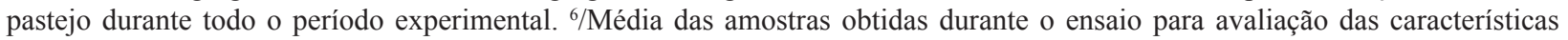
nutricionais. ${ }^{7 /}$ Erro padrão da média.

MM: Mistura mineral; PB17: suplemento múltiplo com 17\% de proteína bruta; PB30: suplemento múltiplo com 30\% de proteína brutaPB43: suplemento múltiplo com 43\% de proteína bruta e PB56: suplemento múltiplo com 56\% de proteína bruta.

Fonte: Elaboração dos autores. 
Nas amostras de forragem obtidas via simulação manual do pastejo e dos concentrados foram quantificados os teores de matéria seca(MS); matéria mineral (MM); proteína bruta $(\mathrm{PB})$, extrato etéreo (EE) e lignina, (SILVA; QUEIROZ, 2002); fibra em detergente neutro (FDNcp), (MERTENS, 2002), utilizando-se $\alpha$-amilase termoestável e omitindo-se o uso de sulfito de sódio, foram realizadas correções para proteína e cinzas na FDN, quantificou-se o teor de nitrogênio insolúvel em detergente neutro (NIDN) e o teor de fibra em detergente ácido (FDA) (VAN SOEST; ROBERTSON, 1985), com correções para proteína e cinzas; fibra em detergente neutro indigestível (FDNi), (VALENTE et al., 2011b), obtida após a incubação em sacos (F57 Ankom $\left.{ }^{\circledR}\right)$ in situ por 288 horas. Nas amostras de forragem destinadas ao cálculo da massa de MS e MSpd foram quantificados os teores de MS; FDNcp e FDNi, conforme descrito anteriormente.

Os carboidratos não fibrosos dos suplementos foram estimados utilizando-se a seguinte equação (HALL; AKINYODE, 2000).

CNFcp $=100-[(\% \mathrm{~PB}-\% \mathrm{PBU}+\%$ de uréia $)+$ $\%$ FDNcp $+\%$ EE $+\%$ de cinzas)

onde: $\mathrm{PBU}=\mathrm{PB}$ no suplemento advinda da ureia.

Nas amostras de forragem para quantificação da massa de matéria seca e de matéria seca potencialmente digestível (MSpd), foram realizadas análises para quantificar os teores de MS, FDNcp e FDNi.

Foi elaborada uma amostra composta de fezes com base no peso seco ao ar, por animal, dos três dias de coleta, as quais foram armazenadas em potes plásticos, devidamente identificadas e posteriormente analisadas quanto aos teores de cromo, por espectrofotometria de absorção atômica (WILLIANS; DAVID; IISMA, 1962); dióxido de titânio por colorimetria (TITGEMEYER et al.,
2001). Avaliaram-se também os teores de MS; PB; EE; FDNcp; FDNi e MM, conforme descrito anteriormente.

A excreção de matéria seca fecal foi estimada utilizando-se o indicador óxido crômico, sendo estimada com base na razão entre a quantidade do indicador fornecido e sua concentração nas fezes:

Matéria seca fecal $\left(\frac{\mathrm{g}}{\mathrm{dia}}\right)=\frac{\text { quantidade fornecida do indicador }(\mathrm{g})}{\text { concentração do indicador nas fezes }(\%)} \times 100$

A estimativa do consumo individual de suplemento pelas novilhas foi obtida através da seguinte equação:

$$
\text { CISup }=((\text { EFxCIFi }) / \text { IFG }) \text { x SupFG }
$$

em que: CISup = consumo individual de suplemento $(\mathrm{kg} / \mathrm{dia}) ; \mathrm{EF}=$ excreção fecal em $\mathrm{kg} / \mathrm{dia} ; \mathrm{CIFi}=$ concentração do indicador nas fezes do animal $(\mathrm{kg} / \mathrm{kg}) ; \mathrm{IFG}=$ indicador presente no suplemento fornecido ao grupo $(\mathrm{kg} / \mathrm{dia})$; $\mathrm{SupFG}=$ quantidade de suplemento fornecida ao grupo de animais $(\mathrm{kg} /$ dia).

A estimação do consumo voluntário de matéria seca foi realizada empregando-se como indicador interno a FDN indigestível, conforme a equação:

\section{CMS $(\mathrm{kg} / \mathrm{dia})=\{[($ EFxCIF $)-\mathrm{IS}] / \mathrm{CIFO}\}+\mathrm{CMSS}$}

em que: $\mathrm{CIF}=$ concentração do indicador nas fezes $(\mathrm{kg} / \mathrm{kg}) ; \mathrm{CIFO}=$ concentração do indicador na forragem $(\mathrm{kg} / \mathrm{kg}) ;$ CMSS = consumo de matéria seca de suplemento (kg/dia); EF = excreção fecal ( $\mathrm{kg} / \mathrm{dia})$; e IS = consumo de indicador a partir do suplemento $(\mathrm{kg})$.

No último dia do ensaio digestivo foram obtidas amostras "spot" de urina, em micção espontânea, 
e de sangue, via punção da veia jugular, realizadas aproximadamente quatro horas após o fornecimento do suplemento. Após a coleta, as amostras de urina foram diluídas com $40 \mathrm{~mL}$ de $\mathrm{H}_{2} \mathrm{SO}_{4}(0,036 \mathrm{~N})$ e congeladas a $-20^{\circ} \mathrm{C}$ para posterior avaliação dos teores de creatinina, uréia e derivados de purina. As amostras de sangue foram coletadas ao final do período de coleta de urina utilizando-se de tubos de vácuo com ativador de coágulo e gel separador (BD Vacuntainer ${ }^{\circledR}$, SST II Advance). O sangue foi imediatamente centrifugado a $2700 \times \mathrm{g}$ por 15 minutos sendo soro armazenado $\left(-20^{\circ} \mathrm{C}\right)$.

Para estimar os teores urinários de ureia foi utilizado o método enzimático-colorimétrico (InVitro ${ }^{\circledR}$, Ureia Liquicolor), para ácido úrico o método enzimático-colorimétrico com fator clareante de lípedes (InVitro ${ }^{\circledR}$, Uric Acid Liquicolor), e os teores de creatinina foram estimados pelo método de Jaffé modificado (InVitro ${ }^{\circledR}$, Creatinina). O cálculo do volume urinário diário foi feito empregando-se a relação entre a excreção diária de creatinina (EC), adotando-se como referência a equação proposta por Chizzotti et al. (2006), e a sua concentração nas amostras "spot":

$$
\operatorname{EC}\left(\frac{\mathrm{mg}}{\mathrm{kgPC}}\right)=32,27-0,010933 \times \mathrm{PC}
$$

em que: $\mathrm{PC}=$ peso corporal.

As análises de alantoína foram feitas pelo método colorimétrico (CHEN; GOMES, 1992). A excreção total de derivados de purinas foi calculada pela soma das quantidades de alantoína e ácido úrico excretados na urina.

As purinas absorvidas (Y, mmol/dia) foram calculadas a partir da excreção de derivados de purinas $\left(\mathrm{X}, \mathrm{mmol}^{\mathrm{d}} \mathrm{dia} \mathrm{a}^{-1}\right)$, por intermédio da equação

$$
P A=\frac{D P-0,301 \times P C^{0,75}}{0,80}
$$

em que: 0,80 é a recuperação de purinas absorvidas como derivados de purinas e $0,301 \times \mathrm{PC}^{0,75}$, a contribuição endógena para a excreção de purinas (BARBOSA et al., 2011).

A síntese ruminal de compostos nitrogenados (Y, g Nmic.dia ${ }^{-1}$ ) foi calculada em função das purinas absorvidas (X, mmol.dia ${ }^{-1}$ ), (BARBOSA et al., 2011)

$$
N_{\text {mic }}=\frac{70 \times P A}{0,83 \times R \times 1000}
$$

em que: $\mathrm{N}_{\text {mic }}=$ fluxo de compostos nitrogenados microbianos no intestino delgado $\left(\right.$ g.dia $\left.{ }^{-1}\right) ; \mathrm{R}=$ relação $\mathrm{N}_{\mathrm{RNA}}: \mathrm{N}_{\text {TOTAL }}$ nas bactérias; 70 = conteúdo de nitrogênio nas purinas $\left(\mathrm{mg} \cdot \mathrm{mmol}^{-1}\right)$; e $0,83=$ digestibilidade intestinal das purinas microbianas. Adotou-se a relação $\mathrm{N}_{\mathrm{RNA}}: \mathrm{N}_{\text {TOTAL }}$ de 0,134 (VALADARES et al., 1999).

Utilizou-se o PROC MIXED do SAS (Statistical Analysis System, versão 9.2) em todas as análises estatísticas. Para todos os procedimentos estatísticos foi adotado $\alpha=0,10$. As comparações entre as médias observadas foram realizadas por meio da decomposição da soma de quadrados para tratamentos em contrastes ortogonais relativos à comparação entre suplementação com suplemento múltiplo e não suplementação, e o efeito linear, quadrático e cúbico para os teores de proteína bruta nos suplementos, utilizou-se o peso corporal inicial como co-variável.

\section{Resultados}

As massas médias de MS e MSpd durante todo o período experimental foram de 5093,5 e 3335,1 kg.ha ${ }^{-1}$, respectivamente. A massa média de MSpd momentaneamente disponível foi de $142,8 \mathrm{~g} / \mathrm{kg}$ de PC, que possivelmente pode ser considerada como não restritiva em relação a possibilidade de maximização de consumo de forragem. A Uruchloa decumbens obtida via simulação do pastejo durante todo o período experimental apresentou teor médio de proteína bruta (PB) de 126,6 g de PB. $\mathrm{kg}^{-1}$ de MS. 
O ganho médio diário de peso (GMD) e o peso corporal final (PCF) foram maiores para os animais suplementados $(\mathrm{P}<0,10)$. Observou-se efeito cúbico do nível de proteína bruta nos suplementos sobre o GMD e PCF (Tabela 3).

Tabela 3. Médias, desvio padrão e indicativos de significância para peso corporal inicial, peso corporal final e ganho médio diário para as novilhas suplementados e não suplementadas durante a estação das águas.

\begin{tabular}{|c|c|c|c|c|c|c|c|c|c|c|}
\hline \multirow[b]{2}{*}{ Item } & \multicolumn{5}{|c|}{ Suplementos } & \multirow{2}{*}{$\begin{array}{l}\text { Desvio } \\
\text { padrão }\end{array}$} & \multicolumn{4}{|c|}{ Valor $-\mathrm{P}^{1}$} \\
\hline & $\mathrm{MM}$ & $\mathrm{PB}_{17}$ & $\mathrm{~PB}_{30}$ & $\mathrm{~PB}_{43}$ & $\mathrm{~PB}_{56}$ & & $\mathrm{CO}$ & $\mathrm{L}$ & Q & $\mathrm{C}$ \\
\hline $\begin{array}{l}\text { Peso corporal } \\
\text { inicial }^{2}\end{array}$ & 229,4 & 231,9 & 227,1 & 228,9 & 229,4 & & & & & \\
\hline $\begin{array}{l}\text { Peso corporal } \\
\text { final }^{2,4}\end{array}$ & 278,8 & 290,6 & 300,3 & 294,7 & 294,7 & 7,138 & $<.0001$ & 0,5442 & 0,0698 & 0,0848 \\
\hline $\begin{array}{l}\text { Ganho médio } \\
\text { diário }^{3,5}\end{array}$ & 447,7 & 554,6 & 638,4 & 587,9 & 590,4 & 0,064 & $<.0001$ & 0,5831 & 0,0894 & 0,0842 \\
\hline
\end{tabular}

1/Indicativos de significância para contraste entre animais suplementados e não suplementados (CO) e para efeito de ordem linear (L), quadrática (Q) e cúbica (C) do nível de proteína bruta nos suplementos. ${ }^{2 /} \mathrm{em} \mathrm{kg.}{ }^{3 /}$ em gramas. ${ }^{4 /} \hat{\mathrm{Y}}=252,75+67,6870 \mathrm{x}-$ $30,5001 x^{2}-4,0620 x^{3}\left(R^{2}>0,9999\right) .5 / \hat{Y}=0,1493+0,6285 x-0,2544 x^{2}-0,0312 x^{3}\left(R^{2}>0,9999\right)$.

MM: Mistura mineral; PB17: suplemento múltiplo com 17\% de proteína bruta; PB30: suplemento múltiplo com 30\% de proteína bruta; PB43: suplemento múltiplo com 43\% de proteína bruta e PB56: suplemento múltiplo com 56\% de proteína bruta.

Fonte: Elaboração dos autores.

$\mathrm{Na}$ Tabela 4 são apresentadas as estimativas do consumo médio diário em kg.dia ${ }^{-1}$ e em g.kg1 de PC em função dos diferentes suplementos. Observou-se maior consumo de MS, MO, PB, EE, CNF, NDT e matéria seca digerida (MSD) $(\mathrm{P}<0,10)$ para os animais suplementados em relação aos não suplementados. Quando expressos em $\mathrm{g} / \mathrm{kg}^{-1}$ de PC observou-se menor consumo de MS e MO pelos não animais suplementados, reflexo do menor consumo de matéria seca total observado para estes animais.

Entre os níveis de proteína bruta nos suplementos observou-se redução no consumo de matéria seca de forragem (MSF) quando se aumentou o nível de PB no suplemento. Como reflexo da redução do consumo de forragem, observou-se efeito linear decrescente sobre o consumo de $\mathrm{MS}, \mathrm{MO}$, matéria orgânica de forragem (MOF), CNF, MSD, fibra em detergente neutro digerida (FDND), NDT e FDNi. Observou-se efeito quadrático do nível de proteína bruta no suplemento sobre o consumo de EE e PB (Tabela 4).

A suplementação aumentou o coeficiente de digestibilidade da MS, PB, EE e CNF. Esta elevação na digestão da PB, EE e CNF, implicaram em maiores estimativas da digestibilidade total da MO e do teor de NDT nas rações dos animais suplementados (Tabela 5).

Houve efeito quadrático do nível de proteína bruta nos suplementos sobre a digestibilidade da MS e EE e efeito cúbico sobre a digestibilidade da MO, FDNcp, CNF e para o teor de NDT. 
Tabela 4. Médias, desvio padrão e indicativos de significância para o consumo voluntário de novilhas em pastejo recebendo suplementos com diferentes teores de proteína bruta.

\begin{tabular}{|c|c|c|c|c|c|c|c|c|c|c|}
\hline \multirow{2}{*}{ Item $^{1}$} & \multicolumn{5}{|c|}{ Suplementos } & \multirow{2}{*}{$\begin{array}{l}\text { Desvio } \\
\text { padrão }\end{array}$} & \multicolumn{4}{|c|}{ Valor $-\mathrm{P}^{2}$} \\
\hline & MM & $\mathrm{PB}_{17}$ & $\mathrm{~PB}_{30}$ & $\mathrm{~PB}_{43}$ & $\mathrm{~PB}_{56}$ & & $\mathrm{CO}$ & $\mathrm{L}$ & $\mathrm{Q}$ & $\mathrm{C}$ \\
\hline \multicolumn{11}{|c|}{$\mathrm{Kg}^{\mathrm{dia}}{ }^{-1}$} \\
\hline Matéria seca ${ }^{3}$ & 5,526 & 7,225 & 7,182 & 6,476 & 5,810 & 1,148 & 0,0232 & 0,0106 & 0,4582 & 0,7105 \\
\hline Matéria seca de forragem ${ }^{4}$ & 5,526 & 6,342 & 6,247 & 5,713 & 5,033 & 1,149 & 0,5270 & 0,0202 & 0,4859 & 0,8779 \\
\hline Matéria orgânica ${ }^{5}$ & 5,152 & 6,664 & 6,603 & 5,875 & 5,369 & 1,051 & 0,0347 & 0,0087 & 0,5473 & 0,6144 \\
\hline Matéria orgânica de forragem 6 & 5,152 & 5,799 & 5,698 & 5,146 & 4,615 & 1,051 & 0,7147 & 0,0195 & 0,5739 & 0,7854 \\
\hline Proteína Bruta ${ }^{7}$ & 0,692 & 0,930 & 1,055 & 1,126 & 0,999 & 0,147 & $<.0001$ & 0,2452 & 0,0234 & 0,5524 \\
\hline Extrato Etéreo $^{8}$ & 0,087 & 0,132 & 0,164 & 0,141 & 0,108 & 0,023 & $<.0001$ & 0,0138 & 0,0006 & 0,2505 \\
\hline FDNcp ${ }^{9}$ & 3,145 & 3,696 & 3,579 & 3,022 & 2,904 & 0,631 & 0,5614 & 0,0063 & 0,9971 & 0,3998 \\
\hline Carboidratos não fibrosos ${ }^{10}$ & 1,227 & 1,909 & 1,795 & 1,633 & 1,358 & 0,250 & 0,0001 & 0,0001 & 0,4813 & 0,9339 \\
\hline Matéria seca digerida ${ }^{11}$ & 3,321 & 4,471 & 4,646 & 4,120 & 3,673 & 0,725 & 0,0054 & 0,0164 & 0,2441 & 0,5145 \\
\hline $\mathrm{FDND}^{12}$ & 2,247 & 2,683 & 2,518 & 2,075 & 2,028 & 0,451 & 0,6787 & 0,0020 & 0,7193 & 0,3668 \\
\hline Nutrientes digestíveis totais ${ }^{13}$ & 3,356 & 4,467 & 4,711 & 4,078 & 3,673 & 0,720 & 0,0066 & 0,0128 & 0,2210 & 0,3546 \\
\hline $\mathrm{FDNi}^{14}$ & 1,019 & 1,181 & 1,193 & 1,127 & 0,985 & 0,211 & 0,2533 & 0,0593 & 0,3202 & 0,9929 \\
\hline Relação NDT/PB ${ }^{15}$ & 4,816 & 4,794 & 4,434 & 3,589 & 3,668 & 0,163 & $<.0001$ & $<.0001$ & 0.0006 & $<.0001$ \\
\hline \multicolumn{11}{|c|}{ g.kg-1 de peso corporal } \\
\hline Matéria seca ${ }^{16}$ & 20,48 & 26,35 & 25,47 & 23,59 & 21,65 & 4,171 & 0,0379 & 0,0218 & 0,7294 & 0,8904 \\
\hline Matéria seca de forragem ${ }^{17}$ & 20,48 & 23,12 & 22,11 & 20,7 & 18,75 & 4,146 & 0,6954 & 0,0344 & 0,7590 & 0,9782 \\
\hline Matéria orgânica ${ }^{18}$ & 19,11 & 24,31 & 23,42 & 21,41 & 19,94 & 3,766 & 0,0525 & 0,0164 & 0,8315 & 0,7867 \\
\hline Matéria orgânica de forragem ${ }^{19}$ & 19,11 & 21,14 & 20,16 & 18,64 & 17,19 & 3,801 & 0,9069 & 0,0338 & 0,8638 & 0,9205 \\
\hline $\mathrm{FDNcp}^{20}$ & 11,66 & 13,46 & 12,67 & 10,95 & 10,81 & 2,291 & 0,7434 & 0,0120 & 0,6910 & 0,5064 \\
\hline $\mathrm{FDNi}^{21}$ & 3,77 & 4,29 & 4,09 & 3,83 & 3,45 & 0,764 & 0,6485 & 0,0301 & 0,7641 & 0,9814 \\
\hline
\end{tabular}

1/FDNcp: Fibra em detergente neutro corrigida para cinzas e proteínas. FDND: Fibra em detergente neutro digerida. FDNi: fibra em detergente neutro indigestível. ${ }^{2} /$ Indicativos de significância para contraste entre animais suplementados e não suplementados (CO) e para efeito de ordem linear (L), quadrática $(\mathrm{Q})$ e cúbica (C) do nível de proteína bruta nos suplementos. ${ }^{3} / \hat{\mathrm{Y}}=7,9668-05199 \mathrm{x}$ $\left(\mathrm{r}^{2}=0,9493\right) \cdot{ }^{4} / \hat{\mathrm{Y}}=7,0056-0,4718 \mathrm{x}\left(\mathrm{r}^{2}=0,9573\right) \cdot{ }^{5} / \hat{\mathrm{Y}}=7,3406-0,4883 \mathrm{x}\left(\mathrm{r}^{2}=0,9573\right) \cdot{ }^{6} / \hat{\mathrm{Y}}=6,3918-0,4330 \mathrm{x}\left(\mathrm{r}^{2}=0,9716\right) \cdot{ }^{7} / \hat{\mathrm{Y}}=$ $0,6910+0,2991 \mathrm{x}-0,0549 \mathrm{x}^{2}\left(\mathrm{r}^{2}=0,9220\right) .{ }^{8} / \hat{\mathrm{Y}}=0,0086+0,0657 \mathrm{x}-0,0151 \mathrm{x}^{2}\left(\mathrm{r}^{2}=0,9464\right) .{ }^{9} / \hat{\mathrm{Y}}=4,0650-0,3050 \mathrm{x}\left(\mathrm{r}^{2}=0,9318\right)$. ${ }^{10} / \hat{\mathrm{Y}}=2,1245-0,1780 \mathrm{x}\left(\mathrm{r}^{2}=0,9833\right) \cdot{ }^{11} / \hat{\mathrm{Y}}=4,9918-0,3073 \mathrm{x}\left(\mathrm{r}^{2}=0,8336\right) .{ }^{12} / \hat{\mathrm{Y}}=2,9506-0,2486 \mathrm{x}\left(\mathrm{r}^{2}=0,9149\right) .{ }^{13} / \hat{\mathrm{Y}}=5,0206$ $-0,3163 \mathrm{x}\left(\mathrm{r}^{2}=0,7940\right) \cdot{ }^{14} / \hat{\mathrm{Y}}=1,2962-0,0705 \mathrm{x}\left(\mathrm{r}^{2}=0,8483\right) \cdot{ }^{15} / \hat{\mathrm{Y}}=3,260+2,950 \mathrm{x}-1,651 \mathrm{x}^{2}+0,234 \mathrm{x}^{3}\left(\mathrm{R}^{2}>0.9999\right){ }^{16} / \hat{\mathrm{Y}}=28,26$ $-1,5975 \mathrm{x}\left(\mathrm{r}^{2}=0,9736\right) \cdot{ }^{17} / \hat{\mathrm{Y}}=24,8006-1,4550 \mathrm{x}\left(\mathrm{r}^{2}=0,9743\right) .{ }^{18} / \hat{\mathrm{Y}}=26,0487-1,5094 \mathrm{x}\left(\mathrm{r}^{2}=0,9812\right) \cdot{ }^{19} / \hat{\mathrm{Y}}=22,0487-1,3365 \mathrm{x}$ $\left(\mathrm{r}^{2}=0,9906\right) \cdot{ }^{20} / \hat{\mathrm{Y}}=14,3931-0,9595 \mathrm{x}\left(\mathrm{r}^{2}=0,9241\right) .{ }^{21} / \hat{\mathrm{Y}}=4,6100-0,2754 \mathrm{x}\left(\mathrm{r}^{2}=0,9764\right)$.

MM: Mistura mineral; $\mathrm{PB}_{17}$ : suplemento múltiplo com $17 \%$ de proteína bruta; $\mathrm{PB}_{30}$ : suplemento múltiplo com $30 \%$ de proteína bruta $\mathrm{PB}_{43}$ : suplemento múltiplo com $43 \%$ de proteína bruta e $\mathrm{PB}_{56}$ : suplemento múltiplo com $56 \%$ de proteína bruta.

Fonte: Elaboração dos autores. 
Tabela 5. Médias, desvio padrão e indicativos de significância para os coeficientes de digestibilidade aparente total dos componentes da ração para novilhas suplementadas e não suplementadas.

\begin{tabular}{|c|c|c|c|c|c|c|c|c|c|c|}
\hline \multirow[t]{2}{*}{ Item } & \multicolumn{5}{|c|}{ Suplementos } & \multirow{2}{*}{$\begin{array}{l}\text { Desvio } \\
\text { Padrão }\end{array}$} & \multicolumn{4}{|c|}{ Valor $-\mathrm{P}^{1}$} \\
\hline & MM & $\mathrm{PB}_{17}$ & $\mathrm{~PB}_{30}$ & $\mathrm{~PB}_{43}$ & $\mathrm{~PB}_{56}$ & & $\mathrm{CO}$ & $\mathrm{L}$ & Q & $\mathrm{C}$ \\
\hline Matéria Seca ${ }^{2}$ & 0,5963 & 0,6187 & 0,6476 & 0,6414 & 0,6330 & 0,0220 & 0,0002 & 0,3008 & 0,0243 & 0,3703 \\
\hline Matéria Orgânica ${ }^{3}$ & 0,6408 & 0,6583 & 0,6960 & 0,6757 & 0,6658 & 0,0209 & 0,0007 & 0,9421 & 0,0036 & 0,0546 \\
\hline Proteína Bruta ${ }^{4}$ & 0,5949 & 0,5872 & 0,6582 & 0,7510 & 0,7337 & 0,0313 & $<.0001$ & $<.0001$ & 0,0005 & 0,0147 \\
\hline Extrato Etéreo ${ }^{5}$ & 0,3085 & 0,4530 & 0,6005 & 0,5428 & 0,4812 & 0,0781 & $<.0001$ & 0,8300 & 0,0008 & 0,1238 \\
\hline Fibra em Detergente Neutro ${ }^{6}$ & 0,6705 & 0,6549 & 0,6925 & 0,6635 & 0,6689 & 0,0209 & 0,9496 & 0,6974 & 0,0403 & 0,0058 \\
\hline Carboidratos não Fibrosos ${ }^{7}$ & 0,6142 & 0,7133 & 0,7317 & 0,6654 & 0,6359 & 0,0359 & $<.0001$ & $<.0001$ & 0,0728 & 0,0458 \\
\hline Nutrientes Digestíveis Totais ${ }^{8}$ & 0,6035 & 0,6181 & 0,6560 & 0,6361 & 0,6327 & 0,0207 & 0,0008 & 0,4711 & 0,0095 & 0,0358 \\
\hline
\end{tabular}

${ }^{2} / \hat{Y}=0,5771+0,0525 x+0,0097 x^{2}\left(R^{2}=0,8114\right) .{ }^{3 /} \hat{Y}=0,4941+0,2497 x-0,0971 x^{2}+0,0113 x^{3}\left(R^{2}>0,9999\right) .4 / \hat{Y}=0,6687-$ $0,2034 x-0,1434 x^{2}+0,0221 x^{3}\left(R^{2}>0,9999\right) .5 / \hat{Y}=0,2358+0,2796 x+0,0551 x^{2}\left(R^{2}=0,7789\right) .6 / \hat{Y}=0,4510-0,3217 x-0,1342 x^{2}-$ $0,0168 \mathrm{x}^{3}\left(\mathrm{R}^{2}>0,9999\right)$.

$7 / \hat{Y}=0,4886+0,3682 x-0,1638 x^{2}-0,0202 x^{3}\left(R^{2}>0,9999\right) .{ }^{8} / \hat{Y}=0,4481+0,2607 x-0,1031 x^{2}-0,0123 x^{3}\left(R^{2}>0,9999\right)$.

MM: Mistura mineral; $\mathrm{PB}_{17}$ : suplemento múltiplo com $17 \%$ de proteína bruta; $\mathrm{PB}_{30}$ : suplemento múltiplo com $30 \%$ de proteína bruta $\mathrm{PB}_{43}$ : suplemento múltiplo com $43 \%$ de proteína bruta e $\mathrm{PB}_{56}$ : suplemento múltiplo com $56 \%$ de proteína bruta.

Fonte: Elaboração dos autores.

O consumo de nitrogênio, a excreção urinária de nitrogênio (ENU) e a excreção fecal de nitrogênio (EFN) foram aumentadas com a suplementação $(\mathrm{P}<0,10)$. Entre os teores de proteína bruta nos suplementos houve efeito cúbico para ENU e EFN e efeito quadrático para o consumo de nitrogênio.

Comparativamente, os animaisem suplementação excretaram mais nitrogênio $(\mathrm{P}<0,10)$ nas fezes e na urina em comparação àqueles que receberam apenas mistura mineral, sem, contudo, causar alterações $(\mathrm{P}>0,10)$ sobre o balanço de compostos nitrogenados (Tabela 6).
As médias de NUS para os animais suplementados aumentaram de forma linear com o aumento no teor de PB nos suplementos. As médias foram iguais a 17,78; 23,86; 26,98 e 28, $17 \mathrm{mg} \cdot \mathrm{dL}^{-1}$, respectivamente para os tratamentos $\mathrm{PB}_{17} ; \mathrm{PB}_{30}$; $\mathrm{PB}_{43}$ e $\mathrm{PB}_{56}$.

A eficiência de síntese de proteína microbiana (EFIM) não foi alterada $(\mathrm{P}>0,10)$ quando comparados animais com suplementação e sem suplementação, com média global de 141,61 g PB microbiana. $\mathrm{kg}^{-1}$ de NDT. Entre os animais suplementados, observouse aumento linear na EFIM com o aumento do nível de PB nos suplementos. 


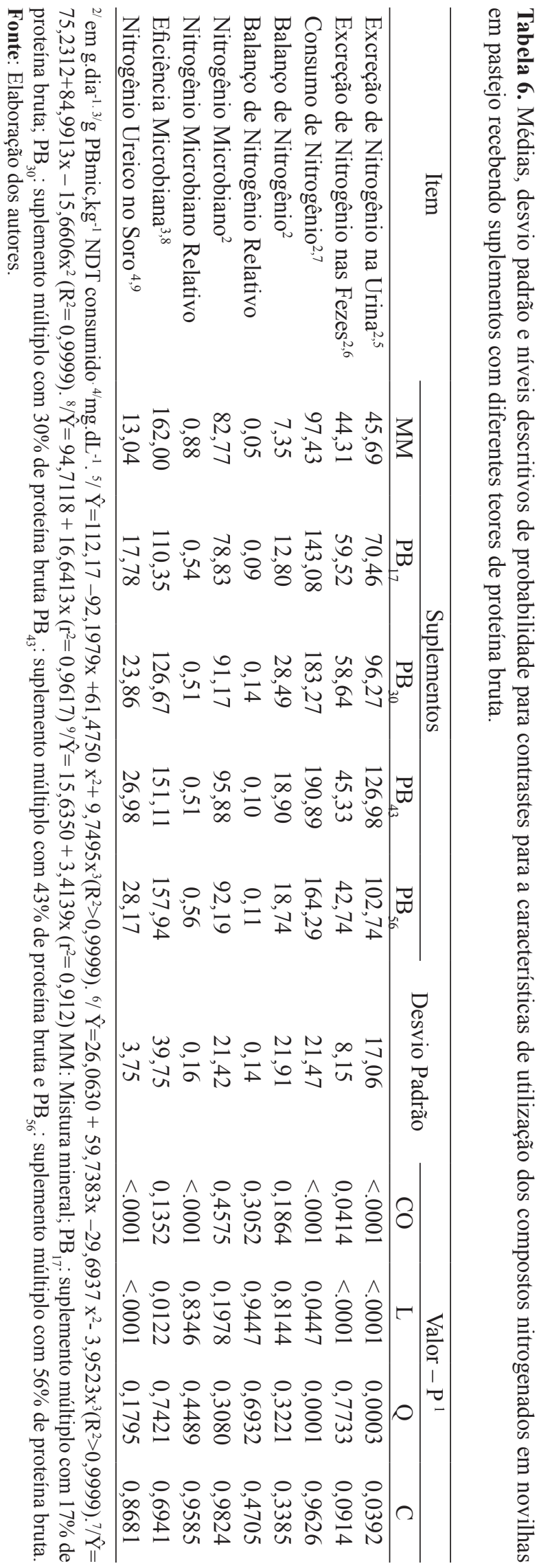

\section{Discussão}

O desempenho produtivo dos animais criados a pasto está diretamente relacionado com a qualidade e a quantidade de forragem disponível para o pastejo, estas características influenciam no consumo de nutrientes e atributos nutricionais pelos animais em pastejo, sendo o consumo o principal determinante do desempenho do animal. Quanto maior a disponibilidade e a qualidade do recurso forrageiro basal, menor a necessidade de adicionar recursos externos ao sistema para aperfeiçoar a produção animal e maior será a eficiência biológica e econômica do sistema.

Neste estudo o raciocínio se deu com base na MSpd do pasto, cuja recomendação feita por Paulino et al. (2004) seria a oferta de 40 a $50 \mathrm{~g}$ de MSpd de pasto. $\mathrm{kg}^{-1} \mathrm{de} \mathrm{PC}$ dos animais para haver desempenho satisfatório dos animais criados a pasto. A massa de MSpd expressa em função do peso corporal (PC), remete a idéia quantitativa e qualitativa da forragem disponível momentaneamente ao animal, independente da taxa de lotação (VALENTE et al., 2011a).

A Uruchloa decumbens obtida via simulação do pastejo durante todo o período experimental apresentou teor médio de proteína bruta $(\mathrm{PB})$ de 126,6 g de PB. $\mathrm{kg}^{-1}$ de MS (Tabela 2), estando acima do valor $70-80 \mathrm{~g}$ de $\mathrm{PB} / \mathrm{kg}$ de MS na dieta basal relatado por Lazzarini et al. (2009) como necessário para que haja adequado aproveitamento da fibra em detergente neutro (FDN) da forragem basal de baixa qualidade, que é a principal fonte de energia para os animais criados a pasto e acima dos $100 \mathrm{~g}$ de PB. $\mathrm{kg}^{-1}$ de MS citados por Sampaio et al. (2009), como ótimo para maximizar o consumo de pasto.

No entanto, apesar da forragem consumida pelos animais ter apresentado teor de nitrogênio superior ao mínimo necessário para que haja adequado aproveitamento da fibra em detergente neutro (FDN) da forragem basal, verificou-se que $25 \%$ deste nitrogênio estavam lentamente disponível para o animal, ou seja, na forma de nitrogênio insolúvel 
em detergente neutro (NIDN) (Tabela 2); o que reforça a importância do fornecimento de fontes suplementares de nitrogênio mais rapidamente disponíveis. Como a forragem é a forma mais econômica e prática na alimentação de bovinos, torna-se prioridade aumentar a sua utilização via aumento no consumo e na disponibilidade de seus nutrientes. Neste estudo, os animais suplementados apresentaram ganho médio diário (GMD) superior aos animais não suplementados $(\mathrm{P}<0,10)$ (Tabela 3 ) apesar da massa forragem disponível ter sido alta, com alto teor de proteína bruta, e com teor energético de $60,35 \%$ (Tabela 5), sendo portanto a forragem considerada de média a alta qualidade, Entre os níveis de proteína bruta nos suplementos houve efeito cúbico no GMD e no peso corporal final dos animais. A possível explicação para o efeito cúbico observado é que o tratamento com 30\% de proteína bruta $\left(\mathrm{PB}_{30}\right)$ apresentou efeito proeminente sobre os demais tratamentos. Segundo Paulino, Detmann e Valadares Filho (2008), existe um ganho latente de cerca de $200 \mathrm{~g} /$ animal.dia ${ }^{-1}$ durante o período das águas que deve ser explorado com o uso de recursos suplementares. Neste estudo, os animais que receberam o suplemento $\mathrm{PB}_{30}$ tiverem um ganho adicional de 190,7 g.dia ${ }^{-1}$, quando comparado aos animais do tratamento controle, o que representou um incremento de $42 \%$ no GMD das novilhas.

$\mathrm{Na}$ Tabela 4 são apresentadas as estimativas do consumo médio diário em kg.dia ${ }^{-1}$ e em g.kg${ }^{1}$ de PC em função dos diferentes suplementos. Observou-se maior consumo de MS, MO, PB, EE, CNF, NDT e matéria seca digerida (MSD) $(\mathrm{P}<0,10)$ para os animais suplementados em relação aos não suplementados; como os teores destes nutrientes são relativamente baixos na forragem basal, era de se esperar que houvesse um aumento significativo de sua ingestão com o fornecimento de fontes suplementares.

Não foram verificados efeitos positivos da suplementação com compostos nitrogenados sobre o consumo voluntário de forragem (Tabela 4). Este comportamento corrobora os resultados obtidos por outros autores em condições tropicais ao fornecerem suplementos protéicos a bovinos manejados em pastagens durante o período das águas (ZERVOUDAKIS et al., 2008; COSTA et al., 2009; PORTO et al., 2009; LAZZARINI, 2011).

A inclusão de compostos nitrogenados suplementares na dieta de bovinos criados a pasto pode ampliar o consumo de compostos da forragem basal até níveis protéicos próximos a 10\% (FIGUEIRAS et al., 2010; SAMPAIO et al., 2010). A partir deste nível dietético de $\mathrm{PB}$, as exigências microbianas em termos de compostos nitrogenados seriam atendidas e nenhum estímulo sobre o consumo de material digerido seria mais observado (DETMANN; PAULINO; VALADARES FILHO, 2010). Estas pressuposições seriam aplicadas às condições do presente estudo, considerando-se o nível médio de PB da forragem basal (126,6 g de PB. $\mathrm{kg}$ de $\mathrm{MS}^{-1}$ ) e a ausência de efeitos da suplementação sobre o consumo de FDNcp digerida (Tabela 4). O teor médio de PB na dieta foi de 12,5; 12,8; 14,6; 17,4 e 17,1 g de PB. kg de MS- ${ }^{1}$, para os tratamentos $\mathrm{MM}, \mathrm{PB}_{17}, \mathrm{~PB}_{30}, \mathrm{~PB}_{43}$ e $\mathrm{PB}_{56}$, respectivamente. Lazzarini (2011), trabalhando com suplementação nitrogenada para bovinos em pastejo não observou aumento no consumo de forragem e FDND com a forragem basal apresentando 134,9 g de PB. $\mathrm{kg}$ de $\mathrm{MS}^{-1}$.

A explicação para o efeito quadrático do teor de PB nos suplementos sobre o consumo de PB e EE é que apesar de consumirem normalmente o suplemento ao longo do período experimental, os animais que receberam o tratamento $\mathrm{PB}_{56}$, $\mathrm{O}$ qual apresentava 5,4\% de ureia/SA reduziram o consumo de suplemento durante o período de avaliação dos parâmetros nutricionais. A sobra de suplemento representou $25 \%$ do total de suplemento fornecido aos animais.

Em vários experimentos nos quais foram utilizados suplementos com altos níveis de PB (normalmente superiores a 50-60\%), foram observados consumos similares de forragem entre 
animais sob suplementação e sem suplementação (ZERVOUDAKIS et al., 2008; COSTA et al., 2009; PORTO et al., 2009), ou seja, ausência de efeito substitutivo. Este efeito também foi observado neste estudo, pois não houve diferença no consumo de matéria seca de forragem entre animais suplementados e não suplementados.

Os efeitos mais proeminentes causados pela suplementação com níveis crescentes de proteína bruta residiram sobre a depressão no consumo voluntário de forragem (Tabela 4). A presença de efeito substitutivo sobre o consumo de forragem não é desejada, uma vez que o objetivo principal da suplementação em pastejo reside sobre a otimização do uso dos recursos forrageiros, promovendo ao mínimo sua substituição (DETMANN et al., 2005).

Efeitos negativos sobre o consumo de pasto com o fornecimento de suplementos proteico-energéticos sob condições de forragem de alta qualidade foram relatados por outros autores em condições tropicais (DETMANN et al., 2001, 2005; PORTO et al., 2008).

Pastos tropicais durante o período das águas apresentam relação energia/proteína acima daquelas demandadas pelos animais, implicando excesso relativo de energia em relação à proteína (DETMANN; PAULINO; VALADARES FILHO, 2010). Sendo assim, o fornecimento de proteína via suplemento pode levar a um equilíbrio na relação energia/proteína e assim aumentar o consumo de forragem e o desempenho dos animais. No entanto, os altos níveis de $\mathrm{PB}$ utilizados neste estudo principalmente para os tratamentos $\mathrm{PB}_{43} \mathrm{e}$ $\mathrm{PB}_{56}$ provavelmente levaram a um desequilíbrio metabólico animal que culminou em redução no consumo de matéria seca de forragem.

A razão entre proteína metabolizável e energia metabolizável aqui representada pela relação NDT/ PB, constitui um dos fatores determinantes do consumo (ILLIUS; JESSOP, 1996).

A ação de mecanismos metabólicos de regulação de consumo também é verificada em condições excessivas de nitrogênio no ambiente ruminal, com excesso de amônia direcionada ao fígado e maior síntese de ureia. Desta forma há um aumento do gasto energético hepático e, consequentemente, uma redução no desempenho produtivo, pois o excesso de metabolismo hepático contribui para a redução da razão energia líquida (EL) / energia metabolizável (EM) por elevar o incremento calórico (DETMANN; PAULINO; VALADARES FILHO, 2010).

Segundo Valadares Filho et al. (2010) a relação NDT/PB ditada pela exigência nutricional para mantença e ganho de $0,5 \mathrm{~kg} /$ dia de fêmeas zebuínas com $250 \mathrm{~kg}$ de PC é de 5,3. Neste estudo, as relações NDT/PB encontradas foram 4,8; 4,7; 4,4; 3,5 e 3,6 para os tratamentos $\mathrm{MM}, \mathrm{PB}_{17}, \mathrm{~PB}_{30}, \mathrm{~PB}_{43}$ e $\mathrm{PB}_{56}$, respectivamente. $\mathrm{O}$ teor de $\mathrm{PB}$ da forragem neste estudo situou-se acima dos patamares normalmente observados em pastos tropicais durante o período das águas (média de 9,42\% relatada por Detmann, Paulino e Valadares Filho (2010). Assim, nas condições do presente estudo, a suplementação com altos teores de PB causou desbalanço dietético o que levou a efeitos negativos sobre o consumo de forragem. Esta observação pode ser confirmada pelos baixos valores da relação NDT/ $\mathrm{PB}$ observados, principalmente para os tratamentos $\mathrm{PB}_{43}$ e $\mathrm{PB}_{56}$. Estes valores baixos indicam que houve um excesso de proteína bruta na dieta dos animais, o que provavelmente elevou o metabolismo hepático de nitrogênio, ampliando o incremento calórico e culminando com a redução do consumo voluntário de forragem.

As exigências de PB e NDT de fêmeas zebuínas com peso corporal igual a $250 \mathrm{~kg}$ e GMD igual a 500 gramas são 594,49 gramas.dia ${ }^{-1}$ e 3,15 kg. dia ${ }^{-1}$, respectivamente (VALADARES FILHO, 2010).

Em todos os tratamentos o consumo de NDT foi acima das exigências de novilhas zebuínas desta categoria para permitir GMD próximo a 500 gramas. Com relação ao consumo de PB todos os tratamentos permitiram consumo de proteína bruta 
igual ou superior ao necessário para permitir o mesmo GMD citado anteriormente. No entanto, como aproximadamente $25 \%$ do nitrogênio estava lentamente disponível para o metabolismo animal, ou seja, na forma de NIDN somente os animais que receberam suplemento múltiplo tiverem GMD acima de $500 \mathrm{~g} /$ dia. Tal resultado pode ser atribuído ao maior consumo de compostos nitrogenados ( $\mathrm{P}<0,10$-Tabela 4) pelos animais suplementados, o que pode ter apresentado efeito benéfico sobre o ambiente ruminal (DIXON; STOCKDALE, 1999), propiciando assim melhor utilização da dieta consumida pelos animais, com maior consumo de matéria seca digerida e consequentemente maior ganho de peso para os animais suplementados.

$\mathrm{O}$ incremento nos coeficientes de digestibilidade total da PB, CNF e EE com a suplementação refletem a maior concentração destes componentes nos suplementos o que incrementa sua participação na dieta total, reduzindo a participação relativa da fração metabólica fecal (VAN SOEST, 1994). Houve efeito quadrático do nível de proteína bruta nos suplementos sobre a digestibilidade da MS e EE e efeito cúbico sobre a digestibilidade da MO, FDNcp, CNF e para o teor de NDT. A possível explicação para os efeitos cúbicos observados é o fato do tratamento com 30\% de PB (PB30) ter apresentado efeito proeminente sobre os demais para estas variáveis. A digestibilidade aparente total da PB também apresentou efeito cúbico, no entanto para esta variável o tratamento PB30 não apresentou efeito proeminente sobre os demais. A digestibilidade da FDNcp não foi afetada pela suplementação o que reflete o fato de a forragem basal não apresentar limitações na disponibilidade de compostos nitrogenados para o crescimento dos microrganismos fibrolíticos.

A digestibilidade aparente total da PB, pode ter sido influenciada pela maior participação de ureia na composição dos suplementos com altos níveis de proteína bruta, visto que a ureia é rapidamente hidrolisada à amônia no ambiente ruminal, o que pode ter elevado as perdas de nitrogênio no rúmen. Esta também pode ter sido influenciada pela redução no consumo de suplemento pelos animais do tratamento PB56 durante o período de avaliação dos parâmetros nutricionais.

Considerando a importância da síntese microbiana para o metabolismo proteico dos ruminantes, é importante conhecer a eficiência na produção de proteína microbiana, fonte de aminoácidos de alta qualidade disponível para absorção e que possui digestibilidade intestinal aproximadamente de $85 \%$ e perfil de aminoácidos constante (SCHWAB, 1996). Nenhum efeito foi observado $(\mathrm{P}>0,10)$ sobre a síntese de nitrogênio microbiano (NMIC), cujo valore médio foi de 88,18 g.dia ${ }^{-1}$, respectivamente.

A eficiência de síntese de proteína microbiana (EFIM) não foi alterada $(\mathrm{P}>0,10)$ quando comparados animais com suplementação e sem suplementação, com média global de 141,61 g PB microbiana. $\mathrm{kg}$ de $\mathrm{NDT}^{-1}$. Valor um pouco acima da referencia para condições tropicais que é $120 \mathrm{~g}$ de PBMic.kg de NDT (VALADARES FILHO, 2010). O maior valor para EFIM observada neste estudo pode ser devido ao fato da forragem consumida pelos animais ter sido considerada de média a alta qualidade.

Entre os teores de proteína bruta nos suplementos, observou-se efeito linear positivo do nível de proteína bruta sobre a EFIM $(\mathrm{P}<0,10)$. O efeito linear positivo dos níveis de proteína bruta nos suplementos sobre a EFIM não se deve à maior produção microbiana, visto que não houve efeito do nível de $\mathrm{PB}$ sobre a produção microbiana. $\mathrm{O}$ aumento na EFIM observado é devido ao menor consumo de NDT (Tabela 3), uma vez que a EFIM é a razão entre a produção de $\mathrm{PB}$ microbiana e consumo de NDT. O consumo de NDT apresentou efeito linear negativo com o aumento do nível de PB nos suplementos.

A concentração de nitrogênio uréico no soro possui elevada correlação positiva com os teores de PB da dieta (CHIZZOTTI et al., 2006; HOJMAN et al., 2004). 
Valadares et al. (1997) sugeriram que os teores de N-ureia plasmáticas entre 13,52 e 15,15 mg.dL $\mathrm{dL}^{-1}$ correspondem à máxima eficiência microbiana $\mathrm{e}$ provavelmente seria o limite no qual ocorre perda de proteína para novilhos zebuínos alimentados com $62,5 \%$ de NDT. Neste estudo o valor médio de NUS para os animais não suplementados foi de 13,04 mg. dL ${ }^{-1}$ valor este próximo do citado por Valadares et al. (1997) para máxima eficiência microbiana. As médias de NUS para os animais suplementados aumentaram de forma linear com o aumento no nível de PB nos suplementos. As médias foram iguais a 17,$78 ; 23,86 ; 26,98$ e $28,17 \mathrm{mg} . \mathrm{dL}^{-1}$, respectivamente para os tratamentos $\mathrm{PB}_{17} ; \mathrm{PB}_{30}$; $\mathrm{PB}_{43}$ e $\mathrm{PB}_{56}$. Os altos valores de NUS observados nos animais suplementados com altos níveis de $\mathrm{PB}$ indicam que houve um excesso de proteína bruta na dieta destes animais.

\section{Conclusões}

O fornecimento de suplementos múltiplos para novilhas de corte, manejadas em pasto de média a alta qualidade durante o período das águas, melhora o desempenho produtivo dos animais. $\mathrm{O}$ fornecimento de suplementos com altos níveis de proteína bruta durante o período das águas diminui o consumo de forragem pelos animais.

\section{Agradecimentos}

A primeira autora agradece ao CNPq (Conselho Nacional de Desenvolvimento Científico e Tecnológico) pela concessão da bolsa de PósDoutorado.

\section{Referências}

BARBOSA, A. M.; VALADARES, R. F. D.; VALADARES FILHO, S. C.; PINA, D. S.; DETMANN, E.; LEÃO, M. I. Endogenous fraction and urinary recovery of purine derivatives obtained by different methods in Nellore cattle. Journal of Animal Science, Champaign, v. 89, n. 2, p. 510-519, 2011.
CHEN, X. B.; GOMES, M. J. Estimation of microbial protein supply to sheep and cattle basid on urinary excretion of purine derivatives-an overview of the technical details. Buchsburnd Aberdeen: Ed. Rowett Research Institute, 1992. 21 p.

CHIZZOTTI, M. L.; VALADARES FILHO, S. C.; VALADARES, R. F.; CHIZZOTTI, F. H. M.; CAMPOS, J. M. S.; MARCONDES, M. I; FONSECA, M. A. Consumo, digestibilidade, excreção de uréia e derivados de purina em novilhas de diferentes pesos. Revista Brasileira de Zootecnia, Viçosa, MG, v. 35, n. 4, p. 18131821, 2006.

COSTA, V. A. C.; DETMANN, E.; VALADARES FILHO, S. C.; PAULINO, M. F.; HENRIQUES, L. T.; MANTOVANI, H. C. Degradação in vitro da fibra em detergente neutro de forragem tropical de alta qualidade em função da suplementação com proteína e/ou carboidratos. Revista Brasileira de Zootecnia, Viçosa, MG, v. 38, n. 9, p. 1803-1811, 2009.

DETMANN, E.; PAULINO, M. F.; ZERVOUDAKIS, J. T.; VALADARES FILHO, S. C.; EUCLYDES, R. F.; LANA, R. P.; QUEIROZ, D. S. Cromo e indicadores internos na estimação do consumo de novilhos mestiços, suplementados, a pasto. Revista Brasileira de Zootecnia, Viçosa, MG, v. 30, n. 5, p. 1600-1609, 2001.

DETMANN, E.; PAULINO, M. F.; CECON, P. R.; VALADARES FILHO, S. C.; ZERVOUDAKIS, J. T.; CABRAL, L. S.; LEÃO, M. I.; LANA, R. P.; PONCIANO, N. J. Níveis de proteína em suplementos para terminação de bovinos em pastejo durante o período de transição seca/águas: consumo voluntário e trânsito de partículas. Revista Brasileira de Zootecnia, Viçosa, MG, v. 34, n. 4, p. 1371-1379, 2005.

DETMANN, E.; PAULINO, M. F.; VALADARES FILHO, S. C. Otimização do uso de recursos forrageiros basais. In: SIMPÓSIO DE PRODUÇÃO DE GADO DE CORTE, 7., 2010, Viçosa, MG. Anais... Viçosa, MG: SIMCORTE, 2010. p. 191-240.

DIXON, R. M.; STOCKDALE, R. Associative effects between forages and grains: consequences for feed utilization. Australian Journal of Agricultural Research, Collingwood, v. 50, n. 5, p. 757-773, 1999.

FIGUEIRAS, J. F.; DETMANN, E.; PAULINO, M. F.; VALENTE, T. N. P.; VALADARES FILHO, S. C.; LAZZARINI, I. Intake and digestibility in cattle under grazing supplemented with nitrogenous compounds during dry season. Revista Brasileira de Zootecnia, Viçosa, MG, v. 39, n. 6, p. 1303-1312, 2010.

FIGUEIREDO, D. M.; PAULINO, M. F.; DETMANN, E.; MORAES, E. H. B. K.; VALADARES FILHO, S. 
C.; SOUZA, M. G. Fontes de proteína em suplementos múltiplos para bovinos em pastejo no período das águas. Revista Brasileira de Zootecnia, Viçosa, MG, v. 37, n. 12, p. 2222-2232, 2008.

HALL, M. B.; AKINYODE, A. Cottonseed hulls: working with with a novel fiber source. In: ANNUAL FLORIDA RUMINANT NUTRITION SYMPOSIUM, 11., 2000, Gainesville. Proceedings... Gainesville: Gainesville: University of Florida,2000. p. 179-186.

HOJMAN, D.; KROLL, O.; ADIN, G.; GIPS, M.; HANOCHI, B.; EZRA, E. Relationships between milk urea and production, nutrition and fertility traits in Israeli dairy herds. Journal of Dairy Science, Madison, v. 87, n. 4, p. 1001-1011, 2004.

ILLIUS, A. W.; JESSOP, N. S. Metabolic Constraints on voluntary intake in ruminants. Journal of Animal Science, Champaign, v. 74, n. 12, p. 3052-3062, 1996.

LAZZARINI, I. Desempenho nutricional de bovinos em pastejo durante os períodos de seca e águas suplementados com compostos nitrogenados elou amido. 2011. Tese (Doutorado em Zootecnia) - Departamento de Zootecnia, Universidade Federal de Viçosa, Viçosa, MG.

LAZZARINI, I.; DETMANN, E.; SAMPAIO, C. B.; PAULINO, M. F.; VALADARES FILHO, S. C.; SOUZA, M. A.; OLIVEIRA, F. A. Intake and digestibility in cattle fed low-quality tropical forage and supplemented with nitrogenous compounds. Revista Brasileira de Zootecnia, Viçosa, MG, v. 38, n. 10, p. 2021-2030, 2009.

MERTENS, D. R. Gravimetric determination of amylasetreated neutral detergent fiber in feeds with refluxing in beaker or crucibles: collaborative study. Journal of AOAC International, Gaithersburg, v. 85, n. 6, p. 12171240, 2002.

PAULINO, M. F.; DETMANN, E.; VALADARES FILHO, S. C. Suplementação animal em pasto: energética ou protéica? In: SYMPOSIUM ON STRATEGIC MANAGEMENT OF PASTURE, 4., 2006, Viçosa, MG. Proceedings... Viçosa, MG: Departamento de Zootecnia, UFV, 2006. p. 359-392.

PAULINO, M. F.; DETMANN, E.; VALADARES FILHO, S. C. Bovinocultura funcional nos tópicos. In: SYMPOSIUM ON STRATEGIC MANAGEMENT OF PASTURE, 4., 2008. Viçosa, MG. Proceedings... Viçosa, MG: Departamento de Zootecnia, UFV, 2008. p. 275-305.

PAULINO, M. F.; FIGUEIREDO, D. M.; MORAES, E. H. B. K.; PORTO, M. O.; SALES, M. F. S.; ACEDO, T. S.; VILLELA, S. D. J.; VALADARES FILHO,
S. C. Suplementação de bovinos em pastagens: uma visão sistêmica. In: SYMPOSIUM OF BEEF CATTLE PRODUCTION, 4., 2004, Viçosa, MG. Proceedings... Viçosa, MG: Departamento de Zootecnia - UFV, 2004. p. 93-139.

POPPI, D. P.; MCLENNAN, S. R. Protein and energy utilization by ruminants at pasture. Journal of Animal Science, Champaign, v. 73, n. 1, p. 278-290, 1995.

PORTO, M. O.; PAULINO, M. F.; VALADARES FILHO, S. C.; DETMANN, E.; SALES, M. F. L.; COUTO, V. R. M. Fontes de energia em suplementos múltiplos para bezerros Nelore em creep feeding: desempenho produtivo, consumo e digestibilidade dos nutrientes. Revista Brasileira de Zootecnia, Viçosa, MG, v. 38, n. 7, p. 1329-1339, 2009.

PORTO, M. O.; PAULINO, M. F.; VALADARES FILHO, S. C.; SALES, M. F. L.; DETMANN, E.; CAVALI, J. Formas de utilização do milho em suplementos para novilhos na fase de terminação em pastagem no período das águas: desempenho e parâmetros nutricionais. Revista Brasileira de Zootecnia, Viçosa, MG, v. 37, n. 12, p. 2251-2260, 2008.

SAMPAIO, C. B.; DETMANN, E.; LAZZARINI, I.; SOUZA, M. A.; PAULINO, M. F.; VALADARES FILHO, S. C. Rumen dynamics of neutral detergent fiber in cattle fed low-quality tropical forage and supplemented with nitrogenous compounds. Revista Brasileira de Zootecnia, Viçosa, MG, v. 38, n. 3, p. 560-569, 2009.

SAMPAIO, C. B.; DETMANN, E.; PAULINO, M. F.; VALADARES FILHO, S. C.; SOUZA, M. A.; LAZZARINI, I.; PAULINO, P. V. R.; QUEIROZ, A. C. Intake and digestibility in cattle fed low-quality tropical forage and supplemented with nitrogenous compounds. Tropical Animal Health and Production, Edinburgh, v. 42, n. 7, p. 1471-1479, 2010.

SCHWAB, C. G. Amino acid nutrition of the dairy cow: Current status.In:CORNELL NUTRITION CONFERENCE FOR FEED MANUFACTURES. 58., 1996, Ithaca. Proceedings... Ithaca: Cornell University, 1996. p.1 84-198.

SILVA, D. J.; QUEIROZ, A. C. Análise de alimentos: métodos químicos e biológicos. 3. ed. Viçosa: UFV, 2002. 165 p.

TITGEMEYER, E. C.; ARMENDARIZ, C. K.; BINDEL, D. J.; GREENWOOD, R. H.; LOEST, C. A. Evaluation of titanium dioxide as a digestibility marker for cattle. Journal of Animal Science, Champaign, v. 79, n. 4, p. 1059-1063, 2001. 
VALADARES FILHO, S. C.; MARCONDES, M. I.; CHIZZOTTI, M. L.; PAULINO, P. V. R. Exigências nutricionais de zebuinos puros e cruzados BR-CORTE. 2. ed. Viçosa: DZO - UFV, 2010. 193 p.

VALADARES, R. F. D.; BRODERICK, G. A.; VALADARES FILHO, S. C.; CLAYTON, M. K. Effect of replacing alfalfa silage with high moisture corn on ruminal protein synthesis estimated from excretion of total purine derivatives. Journal of Dairy Science, Madison, v. 82, n. 11, p. 2686- 2696, 1999.

VALADARES, R. F. D.; GONÇALVES, L. C.; RODRIGUEZ, N. M.; VALADARES FILHO, S. C.; SILVA, J. F. C. Níveis de proteína em dietas de bovinos. 2. Consumo, digestibilidade e balanço de compostos nitrogenados. Revista Brasileira de Zootecnia, Viçosa, MG, v. 26, n. 6, p. 1259-1263, 1997.

VALENTE, É. E. L.; PAULINO, M. F.; DETMANN, E.; VALADARES FILHO, S. C.; BARROS, L. V.; ACEDO, T. S.; COUTO, V. R. M.; LOPES, S. A. Levels of multiple supplements or nitrogen salt for beef heifers in pasture during the dry season. Revista Brasileira de Zootecnia, Viçosa, MG, v. 40, n. 9, p. 2011-2019, 2011a.
VALENTE, T. N. P.; DETMANN, E.; QUEIROZ, A. C.; VALADARES FILHO, S. C.; GOMES, D. I.; FILGUEIRAS, J. F. Evaluation of rumen degradation profiles of forages using bags made from different textiles. Revista Brasileira de Zootecnia, Viçosa, MG, v. 40, n. 11, p. 2565-2573, 2011 b.

VAN SOEST, P. J. Nutritional ecology of the ruminant. 2. ed. Ithaca: Cornell University Press, 1994. 476 p.

VAN SOEST, P. J.; ROBERTSON, J. B. Analysis of forages and fibrous foods. Ithaca: Cornell University, 1985. $202 \mathrm{p}$.

WILLIANS, C. H.; DAVID, D. J.; IISMA, O. The determination of chromic oxide in faeces samples by atomic absorption spectrophotometry. Journal of Agricultural Science, Cambridge, v. 59, n. 3, p. 381-385, 1962.

ZERVOUDAKIS, J. T.; PAULINO, M. F.; CABRAL, L. S.; DETMANN, E.; VALADARES FILHO, S. C.; MORAES, E. H. B. K. Suplementos múltiplos de autocontrole de consumo na recria de novilhos no período das águas. Ciência e Agrotecnologia, Lavras, v. 32, n. 6, p. 1968-1973, 2008. 